every woman in the monotonous routine of her daily tasks; and in times of stress it has its solace and its aid for every soldier in the trenches, for every Red Cross nurse, for every army helper, of whatever name, of land or sea or air; for every government official, whether struggling with rusty administrative machinery or with red tape, or the victim of unjust blame, or merely overburdened with the stress of normal work; and for every industria! worker, for every woman patiently knitting socks or ingeniously planning wheatless meals for her family, for every father struggling with the financial burden of wages, taxes and loans, for every mother who has sacrificed her son, for every woman who has given her husband or sweetheart.

Such is the scope of mental hygiene. Such is its message. In a time when the danger of mental disorder is more serious, perhaps, than ever before, and the number needing the help of a sound mental hygiene greater than ever before; when we are just emerging from'the storm and stress of war; when the hearts of men and women at home are still bearing heavy burdens and the morale of the best soldiers is being tested by a strain more severe than that of war; in a time of numerous fads and cults, when men cry, "Lo here and Lo there, is the kingdom of health," mental hygiene preaches its quiet gospel based upon scientific fact and offers the aid of our vastly increased knowledge to those in need of sympathy and aid, a gaspel as significant in peace as in war, as important for children as for adults, as helpful for normal children as for the defective.

\section{MUNICIPAL CONTROL OF DIPHTHERIA.}

BY D. M. Lewis, M.D., New Haven, ConN.

To the community, as well as to the health authorities, the motto taken from Pasteur, "It is within the power of man to banish from the world all infectious diseases," is of life-saving interest from the standpoint of diphtheria. To create any standard for the control of a disease, that method which results in the most positive prevention as contrasted with all other methods should have the basic consideration. With the majority of known infectious diseases there are two factors for prevention when the etinlogy and the method of spread of the dis- ease are known. An illustration in terms of that disease where today the greatest strides in prevention have been made, namely, typhoid fever, is illustrated either by prevention as car. ried out by Japan in their late war by carrier search and sanitation without emergency or continued vaccination against the disease, or that of other countries who have relied on the latter factor primarily. Extended to communities we find that New York City has made an enviable record for two years by primary ac. tion devoted to the finding of earriers among food and milk handlers, with advocating vaccination as the emergency prevention.

If we apply what methods have been brought forward regarding the control of diphtheria, we find that New York City stands sponsor for immunization against the disease as not only preventive, but as emergency treatment as well, based on the demonstration of suscepti. bles by the Schick reaction. Under the age of 18 months all children should be immunized, as the majority of children lose their maternal immunity after the sixth or ninth month; over the age of 18 months the Schick reaction becomes the criterion. It is stated also that those who do not give the reaction are probably permanently immune. The manner of reaching the children is through the homes, institutions and public schools. Adults who come in close contact, especially attendants in contagious disease hospitals, should also be reached. It is also stated that "the immunity developing from the toxin-antitoxin is slow in appearing, and is, therefore, not a reliable safeguard in hospital wards where children are crowded together and suffering from various contagious diseases."

As limitations under this method, we have the ability to reach all children and any chil dren only under the so-called educational responsibility placed directly on those responsi ble for the children. Secondly there is yet a wider limitation as applied to adults. Thirdly, and the essential point of true re sponsibility, as illustrated with typhoid fever, there is an absence of consideration of the sci entific basis factor, the carrier.

When one studies the disease from investigations and observations in the field, there may be found a method which presents prevention from the point of view of true prevention, namely, the carrier. Having shown how such 


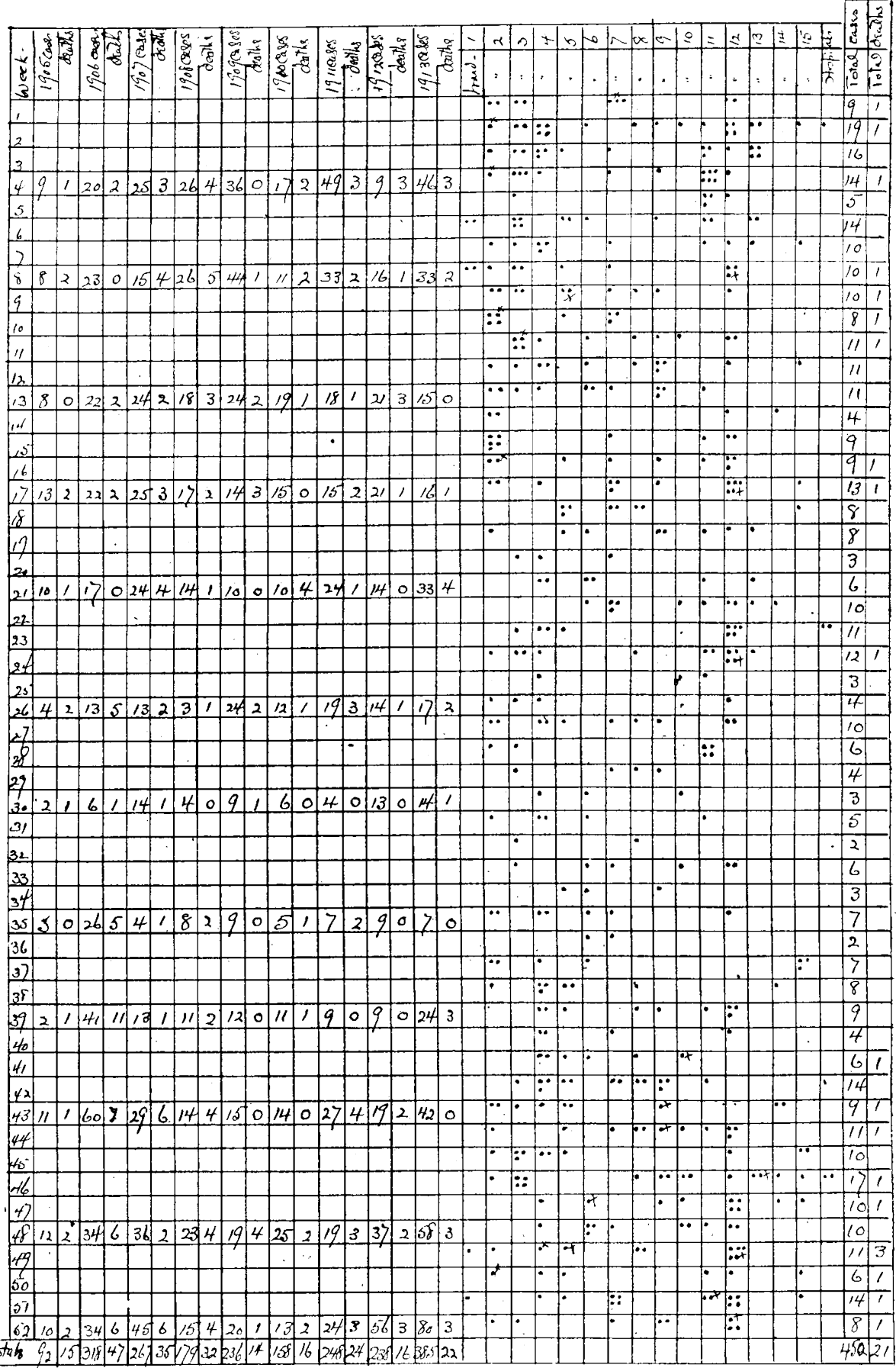

carriers were found, ${ }^{1}$ what the factors were resident for even weeks. Under the system that in making them such, ${ }^{2}$ and the practical I have shown ${ }^{4}$, the weekly visit of the muapplication of the previously demonstrated nicipal communicable disease nurse can have points, $^{3}$ we are in a position to contrast an inspection of such. The importance is this method with the former method. based on the two facts; first, that they are fre-

First, there are no limitations on reaching quently active carriers, as I have shown; secall children, both pre-school and school groups, ondly, if of school age, they would otherwise including those not reached in the former not be found. There is a corresponding wider method, children from out of town, temporary ability to reach adults who are necessary un- 


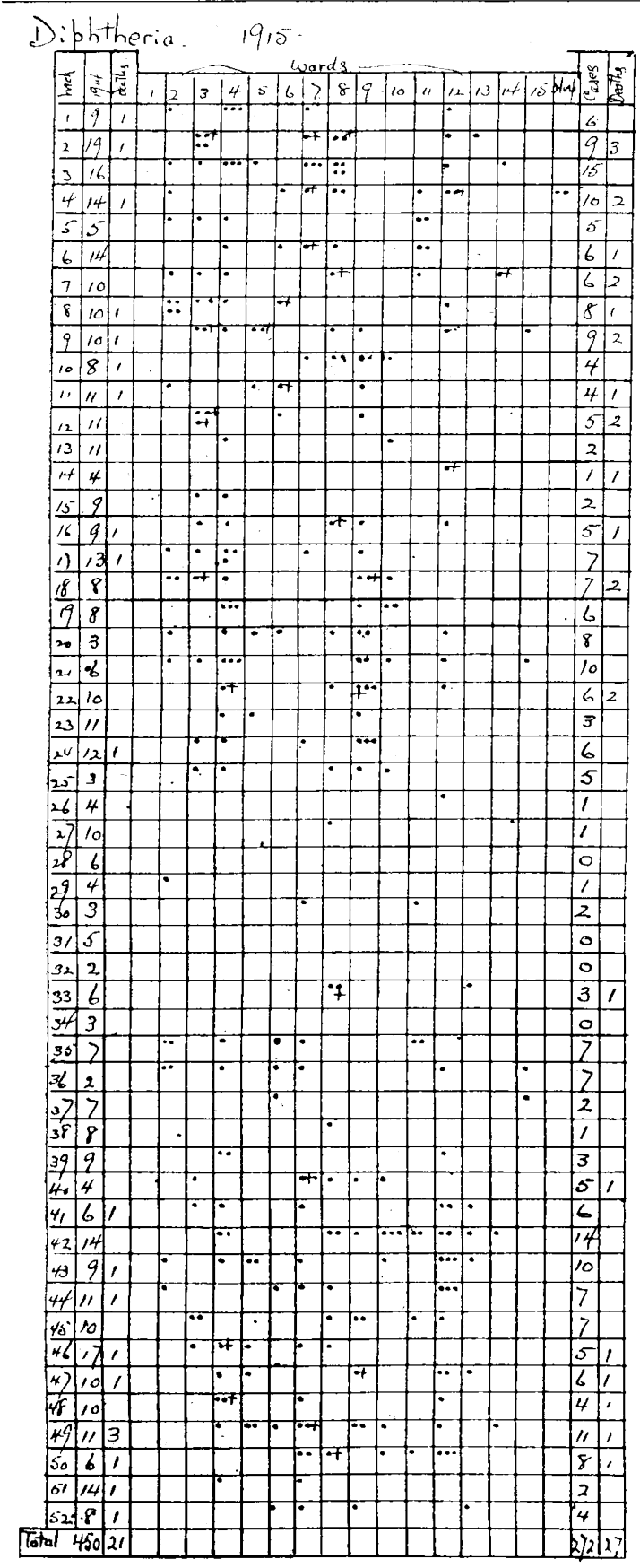

der this system. This is also a measure of the district work of the nurse in ferreting out the communicable disease history of the families in the district. The third limitation of the first method, then, is the basis of our method. As such, a review of the characteristics of the carrier may well be given. Irrespective of whether the carrier is adult or child, whether one who has had the disease previously or not, we present the illustrations, photograph and colored reproduction, as the average picture that we show nurses who are to take up the work as well as those who are similarly responsible in

\begin{tabular}{|c|c|c|c|c|c|c|c|c|c|c|c|c|c|c|}
\hline 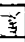 & $=$ & & & 3 & 4 & & 61 & 8 & & 101 & 1.12 & $|13|, 4<0$ & 5404 & 窟 \\
\hline , & 6 & & & & & & & & & & $-x$ & & & \\
\hline 2 & 9 & & & & & & & & & & & & 0 & \\
\hline 3 & is & & & & & & 7 & & & & & & 4 & \\
\hline 4 & 10 & & & & & & & & & & & & 3 & \\
\hline 5 & 5 & & & & & & 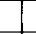 & & & & & & 6 & \\
\hline 6 & 6 & & & & & & 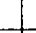 & & & & & & 3 & \\
\hline 2 & 6 & & & & & & 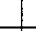 & & & & & & 0 & \\
\hline 3 & 8 & & & & & & $\cdot$ & & & & & & 1 & \\
\hline 2 & 9 & & & & 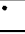 & & & & & & & & 2 & \\
\hline 10 & 4 & & & & & & 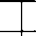 & & & & & & 1 & 1 \\
\hline if & 4 & & & & & & & & & & + & & & 1 \\
\hline 12 & 5 & & & & & & & & & . & & & 2 & \\
\hline 13 & 2 & & & & 't & & • & & & 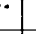 & & & 5 & 1 \\
\hline 4 & 1 & & & & & & & & & & & & 0 & \\
\hline 13 & 2. & & & & . & & & & & & & & 2 & \\
\hline 16 & 5 & & & & & & & & & & & & 1 & \\
\hline .7 & 7 & & & & & & & & & & & & 2 & \\
\hline 18 & 17 & & & & & & & & & & & & 0 & \\
\hline 19 & 6 & & & & & & & & & & & & 2 & \\
\hline 2. & 8 & & & & & & & & & & & & 7 & \\
\hline 21 & 10 & & & & & & & & & & & & 1 & \\
\hline 22 & 6 & & & & . & & & & & & & & 1 & \\
\hline 23 & 3 & & & & & & & & & & & & 0 & \\
\hline 24 & 6 & & & & $\cdot$ & & & & & & & & 1 & \\
\hline 25 & 5 & & & & & & & & & & & & 2 & \\
\hline 26 & 1 & & & & & & & & & & & & 1 & \\
\hline 2) & 1 & & & & & & & & & & & & 1 & \\
\hline 28 & 0 & & & & & & & & & & & & 2 & \\
\hline 25 & 1 & & & & & & & & & & & & 우 & \\
\hline 30 & 2 & & & & & & & & & & & & 이 & \\
\hline 3 & 0 & & & & 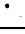 & & & & & & & & 1 & \\
\hline 32 & 0 & & & 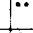 & & & & & & & & & 2 & \\
\hline 3 & 3 & & & & 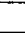 & 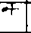 & & & & & & & 2 & 1 \\
\hline 34 & o & & & & & & & & & & & & 1 & \\
\hline 35 & 7 & & & & & & & & & & & & 1 & \\
\hline 36 & 7 & & & “杽 & & & & & & & & & 2 & \\
\hline 37 & 2 & & & $0^{\circ}$ & $0^{\circ}$ & & & & & & & & 2 & \\
\hline 38 & 1 & & & & & & & & 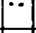 & & & & 3 & \\
\hline 3 & 3 & & & F & & & & & & & & & 2 & 1 \\
\hline 40 & 5 & & & & $\because$ & & L & & & & & & 4 & \\
\hline$*$ & 6 & & & & $\$ 4$ & & & & 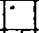 & & & & 11 & I \\
\hline 42. & 14 & & & & 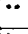 & & & & 17 & & & & 4 & \\
\hline 43 & 10 & & & & & & & & & & & & 4 & A \\
\hline 44 & 2 & & & & & & & & & & & & 3 & \\
\hline 4s & 7 & & & & 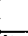 & & & & & & & & 5 & \\
\hline 46 & 5 & & & & & & & & & & & & 1 & \\
\hline t) & 6 & & & & $=\cdots$ & & {[} & & & 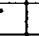 & & & 7 & 2 \\
\hline $4 p$ & 14 & & & & $\%$ & $i$ & & & $\because$ & & & & 2 & 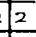 \\
\hline 49 & 11 & 1 & & & - & & & & & & & & 4 & \\
\hline & 8 & & & & & & F & & & & & & 2 & 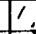 \\
\hline 5 & 2 & & & & 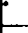 & & $I$ & & & & & & 2 & \\
\hline 2 & 4 & & & & & & . & & & & & & 0 & \\
\hline 1 & 077 & & & & & & & & & & & & 35 & 51 \\
\hline
\end{tabular}

institutions. Whether the presenting bloodypurulent coagulated mass seen protruding from the right nares is externally discoverable, as here shown, or whether a similar picture is seen only between the middle turbinate and the external meatus, necessitating the tilting of the nose, or whether there is exuding seropurulent fluid as well, excoriating or having excoriated with crust formation, the upper lip or even cheeks where finger infection has been transferred to scratches or cuts, I have shown that only what can be seen is the main objective with the corroboration of the culture. 


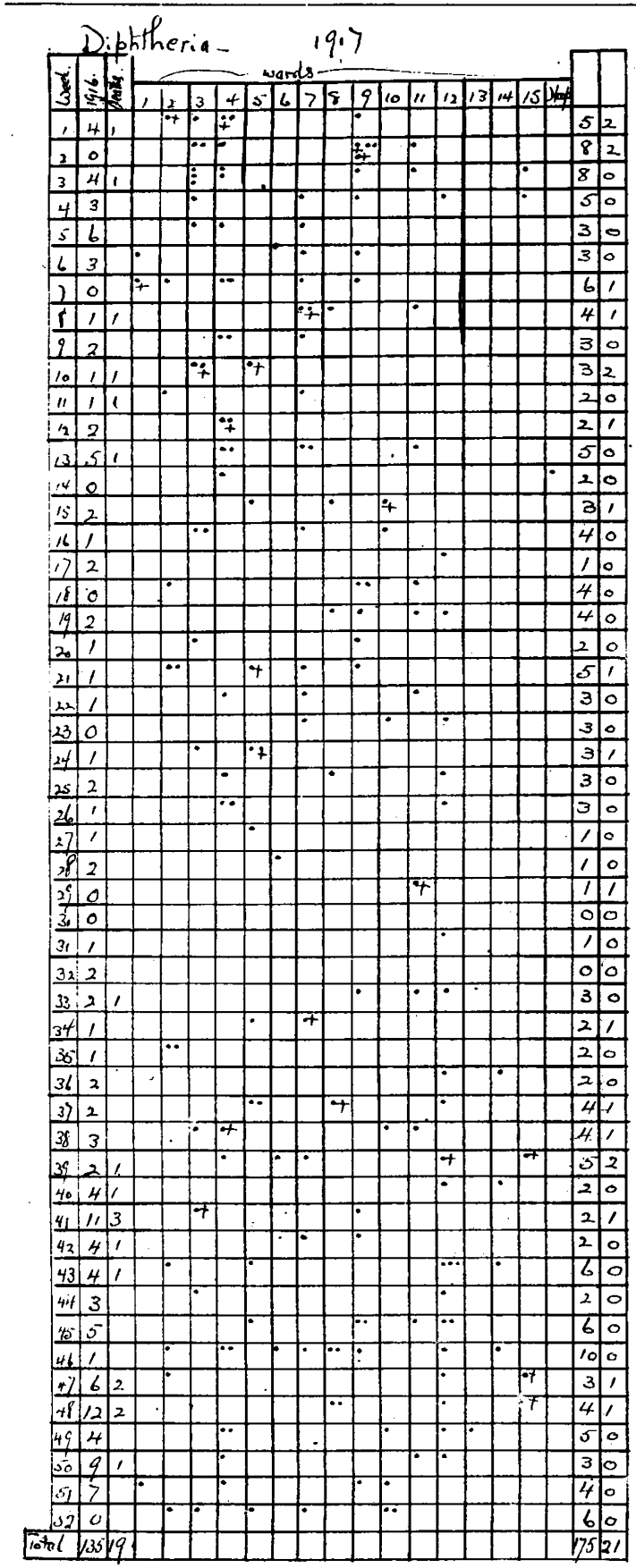

From observations, as I have shown, the activity of the chronic recurring carrier is in terms of recurring head colds and are very definately non-contagious for cases. They are individuals who have had the disease and are the ones generally responsible for further carriers who have not had the disease, but for reason of deformity, generally unilateral, have an ordinary head cold infected directly by such primary carriers. Cases are traceable to the sec. ondary carriers. Their numbers and distribution, whether family, house or neighborhood,

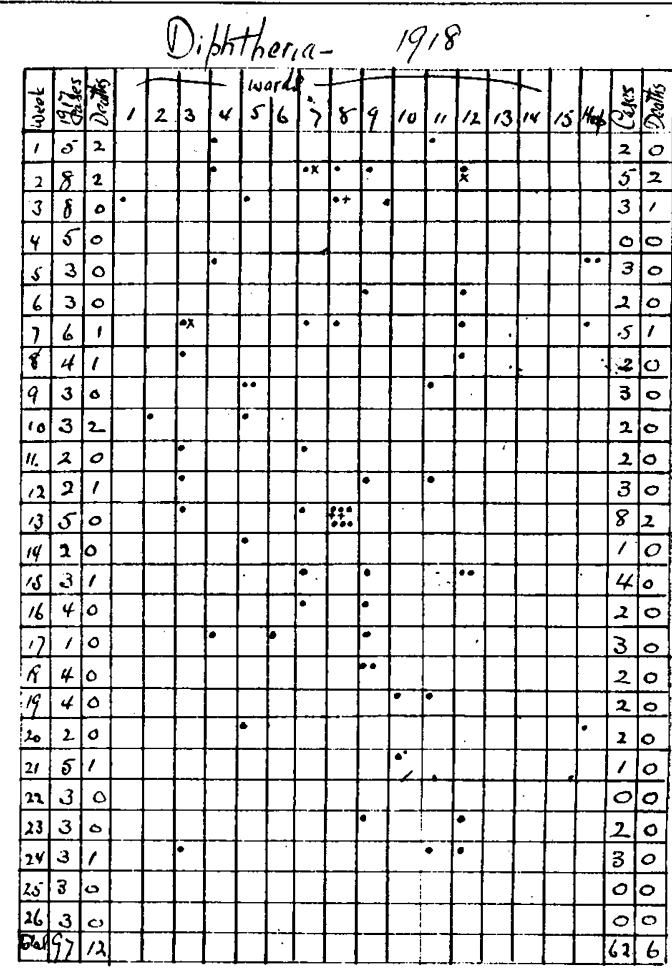

are definitely accounted for, when the carrier is found. Absence of cases for a period of months, even years, during a period of frequency in adjacent wards with a similar previous frequency in the former district are obtainable. This is well illustrated in the appended charts for the years 1917-18 in the 13th ward. Especial stress has been laid by me on the making of carriers during the periods of frequency of grippe and measles. Almost conclusive in itself is to chart the frequency of measles and diphtheria week by week; the records of the four principal cities of this State so charted show regularly by years that following a rise of measles there ensues during the next month the rise of diphtheria with fatalities where previously there had been but few or no cases and no fatalities.

What are the advantages of this method as compared to the former? Based on the experience that only what may be seen is to be looked for and that the what to be looked for is the unusual, if it is accurate, it should give definite results, gain time for larger amount of work by directing procedures for a small proportion of the children or adults, the main gain being in that concerned from cultures, and not require the basis of the former method, active immunization or a procedure for detecting susceptibility. The sum total expressed in terms of responsibility directly assumed by the 


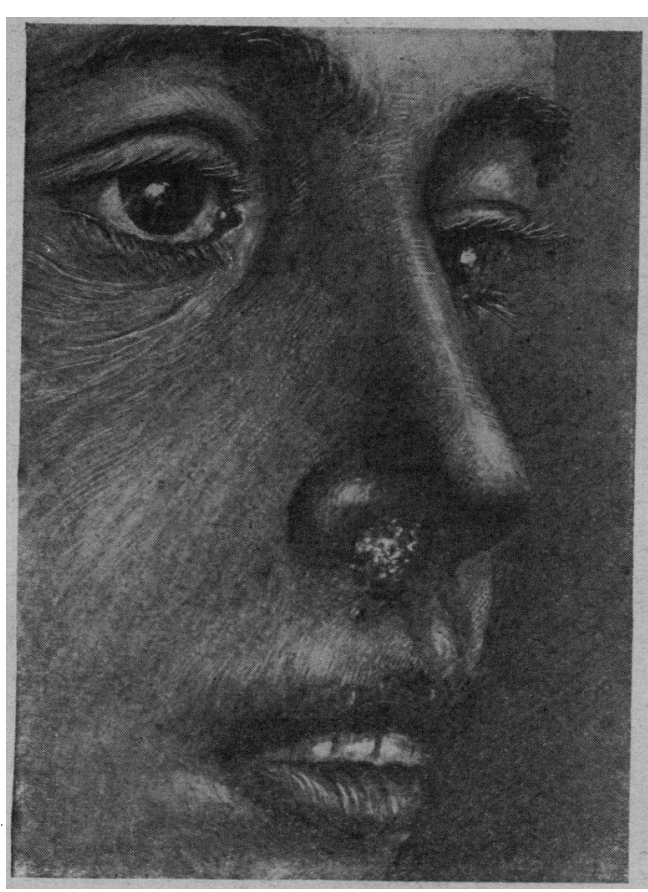

Nasal Carrer of Diphtheria.

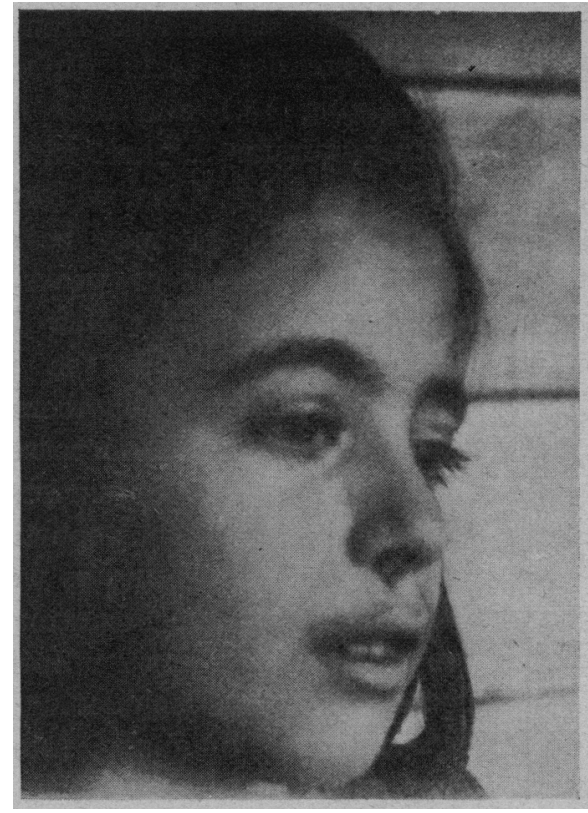

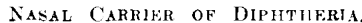

health authorities rather than the latter placing responsibility elsewhere is a basic fundamental.

What are the results in terms of our advantages? I have shown that for three years this city has never had a recurrent case except convalescent nasal carriers were discharged by the hospital with consecutive negative cultures, that secondary family cases have been reduced to the minimum of family disregard for the demonstrated carrier which has been from the standpoint of the attending physician as well, that secondary neighborhood cases have been reduced and, a point appreciated in this city, that during one and one-half years past no house of the better residential section, with but one exception, has had a case of the disease. This exception was related as Case 3 in my "Study of Diphtheria Carriers." If now it is realized that this work characterized the investigation of and prevention of the disease in institutions as well, namely, the Gaylord Farm Sanatorium, and the Orphan Asylum of this eity and was done without the dependence on the Schick reaction, active immunization or prophylactic antitoxin under any circumstances during these years, such results as obtain are the more valuable. The definite assurance of absence of secondary or recurrent cases gained from the first two years' work on the earrier was the warrant for not only not taking up these procedures, but of personally advising against them as time consuming, frequently impossible for complete use of, but especially as misdirecting responsible attention from the basic cause.

Results are definitely those expressed in deaths per 100,000 population when consideration is taken of the factors that cause the similar frequence of the disease ; namely, cities must be compared which have similar climatic conditions, a mixed population and immediately preceding or prevailing respiratory disease frequence. Bridgeport, this State, had, like New Haven, a high frequency of measles in 1917, in terms of deaths 12.5 contrasted with New Haven, 13.5 per 100,000 . The diphtheria rate, respectively, was 20 and 16 . As stated in my "Study of Diphtheria Cariers," the early fall incidence of reported diphtheria was higher than the previous year and was exactly following the ward incidence of previous measles. The measure of two nurses inspecting all children in school and a small proportion in selected districts during December, 1917, and January, 1918, gave the following rates: Bridgeport, for the first quarter 1918, 14; New Haven, 9 ; for the first half year, 1918, the former city, 16; ours, 4 . Extending this to New York the year rate for 1917 was 20 per $100,000,11$ for the first quarter of 1918 and 12 
for the first half year of 1918 . The rise is co- ing 24 hours, and three other children in the incident with the rise in measles during 1918. family were sent a few days later as cases, alSimilar figures may be shown also from such though inspection of them had shown them to as: Boston, 1916, measles, 14.1; diphtheria, be neither carriers nor cases.

24.3 ; and 1917 giving 13.1 and 35.7 respectively. Interesting similar higher rates but corresponding are given by Winslow for cities in Russia. ${ }^{5}$ Further testimony may be shown by the not infrequent number of weeks when there were no reported cases for New Haven during the winter season while the public health reports showed that our neighbors were reporting continued proportional increases. It has been current opinion, in some quarters, that this city was getting away from reporting of diphtheria deaths (even to labelling as well) as grippe, for the reason that the laboratory was doing extensive work on the differentiating of pure streptococcal infections simulating diphtheria and carrying the diagnosis into field work and education. That this had no bearing on the question at issue is shown by the same comparative statistical deaths of the various cities compared, that this city had continued monthly disproportionate lessened total deaths from all communicable diseases as well as those from grippe or streptococeal diagnoses in each and all ages. In itself this was a measure of the finding of such streptococcal carriers.

How trustworthy is nasal inspection only, is a very proper question. So trustworthy that it may be left to institutional nurses after an initial demonstration; that after a similar initial complete school demonstration during the five ensuing months there were but two carriers who got by teachers and caused a single reported found case before the carrier was located. One was the illustration offered, responsibility for which lay with a substitute teacher; one a carrier in a school which did not class themselves as under our jurisdiction. In this connection the reliability of the school absentee card system used by me is shown by the record of the 13 weeks in 1918 for the 8th ward. A substitute teacher failed to return the only absentee not reported in that school for the half year. One week after the day on which we should have had the card for investigation, the absentee and two other children in the family were sent to the hospital by a physician, on his initial call, as diphtheria. The absentee and a brother, a cripple from active tone tuberculosis, were both dead in the ensu-

The appended charts show the incidence of reported and found cases by weeks and by wards for the years I have been working on the disease with, for comparison, that for months for the previous nine years. Deaths are shown by crasses. With measles epidemic in 1917, causing the greatest number of deaths since a similar epidemic in 1906, what follows as well during and after a small frequence in 1914 is well shown by the charts. The greatest number of deaths from diphtheria follow in the first half year during those years immediately following a high measles. The greatest number of deaths during the last half year is during a measles year, or one of grippe, which gives a lesser preponderance. Results, then, are very apparent, not only for the first half year of 1917 over 1914, but even greater over the first half year of 1918 over the similar period of 1915. Similarly, the last half of 1917 shows results in comparison to the similar period of 1914 . If now we state that the results through 1917 were those of carriers as found through our school card system and in connection with reported cases, that measure has given excellent results over other cities having similar conditions, and results over our own city under previous similar conditions. The record of the last month in 1917 and that of the first month of 1918 show what happened when two communicable disease nurses spent all their time systematically seeking carriers, in schools, institutions, and scratching the surface of the pre-school age during the ten days' holidays. Following those two temporary months, one nurse became a permanent appointee. Inasmuch as one nurse could cover little ground systematically or larger areas at random, I picked out the 3rd and 4th wards as the hotbeds of infection as shown by the past records. House by house, street by street this nurse "covered in the following months the half of the 3rd ward where measles had been and whooping cough was preëminent by reason of excess of foreign population, and onethird of the 4th adjacent ward where similar conditions held. Taken in terms of frequency, the records of these two wards in terms of previous years and that relative to the other wards both in terms of 1918 and the latter's record 
for other years is a very striking demonstration of what results may be gotten by our method.

Practical municipal control of a disease is necessarily further bound up in the question of finances. That system which entails a lower cost during epidemic frequency and especially which from any measure of control prevents epidemic frequency is essential. The record of this city from the opening of its isolation hospital for contagious diseases in amounts expended for city cases of diphtheria is as follows: 1915,23 cases, $\$ 1,229$, including one carrier, $\$ 458$; 1916,17 cases, $\$ 1,262.30$, including the carrier mentioned, $\$ 718 ; 1917,33$ cases, $\$ 1,965.34$, including the same carrier, $\$ 736$; 1918 (first half year), 12 cases, $\$ 715$, including the same carrier, $\$ 424$. This record is consistent with our previous results; from the money saved to the municipality for expenditure of city cases of diphtheria alone we have paid in 1918 for the services of one communicable disease nurse, of whose activities such work is but one part.

In sum, municipal control of a disease in theory means practical control in terms of true prevention; in practice it should be able to demonstrate results in conformity to such and in excess of methods not having such a basis. Our results from the standpoint of true prevention, based solely on the carrier, even in the absence of nine-tenths the pre-school age inspection such as is a part of the method expressed in terms of proof, are the warrant that we have a system demonstrating all factors necessary for the control of diphtheria. That this system is operated by a simplicity, a rapidity of directness and a surety of results on all lines, including financial, as should be consistent with personal municipal responsibility, is further expression that we have true municipal control of the disease.

\section{REFERENOES,}

1 Control of Diphtheria. Journ. A. M. A., May 13, 1916.

2 Application of the Factors Controlling Carriers of Communicable

Diseases. Interstate Med. Journ., Vol. $\mathbf{x x v}$, No. 1.

a Atudy of Diphtheria Carriers. Boston Medrcal aND Surgical

JoURNAL, May 2, 1918.

4 The Control of Communicable Diseases. Ibid., June 6, 1918.

5 Public Health Reports. Dec. 28, 1917.

\section{HABIT VERSUS INSTINCT IN EATING.}

By Hugh Payne Greetey, M.D., Madison, Wis.

THE fact that the recent article by Professor Osborne published in the Atlantic Monthly for
September entitled "What and How Much Should We Eat?" can pass unchallenged by the practising physicians of the country, indicates to me the great necessity for studying the practical application of the science of nutriticn as it has been developed in our great nutrition laboratories.

Having for many years been a student of metabolism in its practical bearing in the treatment of disease, I read the above mentioned article with great interest. Such an eminent authority as Dr. Osborne I would not wish to dispute, but I feel that a fuller discussion of certain statements would be helpful.

Professor Osborne makes this statement: "It has been generally held that overeating, except within narrow bounds, is impossible, for the subject will either grow fat, which, of course, has its limits, or will feel badly and cease to eat in excess until a normal condition is established;" and later, in the article, "Can a man overeat habitually without either grow. ing fat or dyspeptic?;" and again, "If surplus food above that needed for the daily tasks of life can be disposed of by increased rate of metabolism, can such a stimulation of metabolism be frequently endured without sensations of discomfort?"

In the practice of medicine the fat mar who from instinct ceases to eat until a normal condition is established does not exist. His instinct must be aided by strong will-power and great self-control and the establishment of a normal condition, seldom, if, ever, takes place from a reconstruction of diet alone. Another class of people certainly can habitually overeat without getting fat or feeling badly, particularly without getting indigestion. It is common knowledge that some people cannot get fat and yet they are without organic cause for leanness. It seems to be a matter of temperament or metabolic rate. It is also common knowledge that these individuals can constantly overeat without sensations of discomfort. Constant overeating may produce one of three things,obesity, indigestion, or metabolic disaster, such as diabetes. Is it not probable that stimulation of the metabolic rate for years might break down metabolic processes in the same way as running a motor with a wide-open throttle will shorten its life through premature exhaustion? Our experience would certainly -corroborate this belief, and explain many cases of diabetes In another place Professor Osborne says: 